\title{
Number of Metastases
}

National Cancer Institute

\section{Source}

National Cancer Institute. Number of Metastases. NCI Thesaurus. Code C142987.

An indication of the number of metastatic tumors detected. 